\title{
O pass-through das variações da taxa de câmbio para os preços dos principais produtos exportados pelo Brasil*
}

\author{
César A. O. Tejada** \\ Agnaldo Gomes da Silva***
}

\begin{abstract}
Resumo: O artigo estuda a relação entre as variações da taxa de câmbio e os preços das exportações dos principais produtos exportados pelo Brasil, o chamado pass-through da taxa de câmbio. Utiliza-se o modelo de parâmetros variáveis no tempo para estimar os coeficientes de pass-through. Os resultados sugerem que o pass-through incompleto das taxas de câmbio predomina nos setores analisados, bem como com relação às exportações totais. Esses resultados confirmam as estimativas de outros estudos e também mostram que o comportamento desse fenômeno, ao longo do tempo, depende do setor analisado.
\end{abstract}

Palavras-chave: coeficiente de pass-through, taxa de câmbio, preços das exportações, Brasil.

Classificação JEL: C22, C50, F12.

\footnotetext{
* Agradecemos a colaboração na pesquisa de Alexandre Lima Costa e Roberto Castro (bolsistas PIBIC/Fapeal). Agradecemos também os comentários de dois pareceristas anônimos. Como é de praxe, eventuais erros remanescentes são de inteira responsabilidade dos autores.

** Professor da FEAC e do Curso de Mestrado em Economia Aplicada da Universidade Federal de Alagoas. E-mail: cesartejada@uol.com.br

*** Professor da FEAC e do Curso de Mestrado em Economia Aplicada da Universidade Federal de Alagoas. E-mail: gomeco@uol.com.br
} 


\begin{abstract}
The aim of the present paper is to analyze the relationship between exchange rates changes and prices of main Brazilian exports, the exchange rate pass-through. A varying-parameter model was used to estimate the coefficients of pass-through. The results suggest that incomplete pass-through of exchange rate changes is a pervasive phenomenon. These results are in line with other estimates presented in the literature.
\end{abstract}

Keywords: exchange rate pass-through, export prices, Brazil.

JEL Classification: C22, C50, F12.

\title{
1. Introdução
}

O pass-through (repasse) das mudanças da taxa de câmbio para os preços comerciáveis de um país constitui-se em uma questão central no debate sobre a eficácia da política cambial no ajuste do balanço de pagamentos. Por exemplo, para motivarem seu survey da literatura sobre os preços e as taxas de câmbio, Goldberg e Knetter (1997) focaram a apreciação da ordem do $34 \%$ do iene face ao dólar americano, entre janeiro de 1994 e abril de 1995. Para esses autores esse episódio levantava certas questões, tais como:

Why was there so little change in the dollar price of imports ...? Was the response simply delayed? Did Japanese exporters perceive the exchange rate change to be only temporary? Does incomplete pass-through imply that Japanese producers slashed markups top the U.S.? Or did they find new ways to offset their increased dollar-equivalent costs?... What can we learn about the nature of competition in international products markets from observations on prices and exchange rates?

O principal achado de Golberg e Knetter (1997, p. 1244) foi: "the local currency prices of foreign products do not respond fully to exchange rates".

Naturalmente, o episódio relatado não é um exemplo isolado na história econômica japonesa, bem como em outras experiências interna- 
cionais. A conclusão geral da maioria de estudos empíricos é que o grau de pass-through da taxa de câmbio para os preços das exportações e das importações é incompleto, e que existem importantes diferenças nas magnitudes estimadas do grau de pass-through. ${ }^{1}$

Quando o pass-throug é nulo, a taxa de câmbio não tem qualquer influência sobre o preço em moeda estrangeira dos bens exportados; portanto, mudanças cambiais afetam apenas as margens de lucro dos exportadores, sem causar impacto sobre a "competitividade" das exportações nacionais. Quando o pass-through é completo, quaisquer mudanças na taxa de câmbio são transmitidas integralmente para o preço em moeda estrangeira dos produtos exportados, afetando, assim, a competitividade da produção doméstica no mercado mundial. Assim, o pass-through das mudanças na taxa de câmbio para os preços das exportações determina o grau de competitividade alcançado a partir de variações na taxa de câmbio. A eficácia da taxa de câmbio como instrumento de política em programas de promoção de exportações e ajustamento da conta corrente do balanço de pagamento, depende, portanto, do coeficiente de pass-through.

Como Goldberg e Knetter (1997) mostram, esses fatos estilizados têm inspirado uma vasta literatura sobre as condições competitivas nos mercados externos e domésticos. A discriminação de preços, a forma funcional da curva de demanda sob monopólio, pressupostos sobre estruturas oligopolistas e outros aspectos são apresentados como possíveis explicações desses fatos.

Nesse contexto, o crescente interesse no desempenho das exportações brasileiras faz com que seja importante analisar a relação entre as variações nas taxas de câmbio e os preços dos produtos exportados, o chamado pass-through das mudanças na taxa de câmbio para os preços das exportações. Como se sabe, a participação das exportações brasileiras sobre o total das exportações mundiais não atingiu 1\% nos últimos anos, embora se espere que essa participação aumente.

Portanto, estudos que estimem os coeficientes de pass-through tornam-se de extrema importância para a determinação da competitividade dos produtos brasileiros no contexto do mercado internacional.

O objetivo deste artigo é analisar os determinantes do pass-through das

${ }^{1}$ Ver um survey da literatura empírica sobre o pass-through da taxa de câmbio em Menon (1995). 
variações da taxa de câmbio para os preços das principais exportações do Brasil. Os setores examinados no trabalho representaram 65,86\% das exportações totais brasileiras, no ano de $2004 .^{2}$ Adicionalmente, para propósitos de comparação, foram analisadas também as exportações totais.

Além desta introdução, o artigo apresenta, na segunda seção, os aspectos teóricos do pass-through da taxa de câmbio; na terceira, uma breve revisão dos estudos empíricos; na quarta, os resultados das estimações dos coeficientes de pass-through para os preços dos principais setores de exportação; no final, são apresentadas as conclusões do artigo.

\section{O pass-through da taxa de câmbio}

Na literatura econômica, a expressão exchange rate pass-through é geralmente usada para referir-se aos efeitos das mudanças das taxas de câmbio sobre um dos seguintes itens: (1) preços aos consumidores; (2) investimentos; (3) volumes de comércio e (4) preços das importações e das exportações.

Como assinalado na introdução, o foco de estudo do artigo é o tópico (4) e, mais especificamente, o pass-through das variações da taxa de câmbio para os preços das exportações. A escolha dessa questão como objeto da pesquisa deve-se a dois fatores: primeiro, porque essa é a base natural para estudar as regras de fixação de preços dos setores exportadores; segundo, porque uma resposta dos preços das exportações às mudanças da taxa de câmbio é usualmente necessária, antes de haver qualquer conseqüência para os preços aos consumidores, o investimento ou os volumes de comércio.

Como mencionado, a situação mais comum encontrada na literatura empírica é de um pass-through incompleto. As principais explicações propostas na literatura econômica para o pass-through incompleto de variações nas taxas de câmbio para os preços dos produtos comerciáveis (bens exportados e importados) podem ser agrupadas em duas: a abordagem das elasticidades e os recentes desenvolvimentos baseados nas

${ }^{2}$ Os setores examinados no trabalho são: Peças e Outros Veículos, Siderurgia, Extrativa Mineral, Máquinas e Tratores, Veículos Automotores, Óleos Vegetais, Refino de Petróleo, Madeira e Mobiliário, Beneficiamento de Produtos Vegetais, Metalurgia de Não-Ferrosos, Celulose Papel e Gráfica, Material Elétrico, Elementos Químicos e Equipamentos Eletrônicos. 
estruturas de mercado e as características dos produtos, e o papel das empresas multinacionais e os efeitos das barreiras não-tarifárias ${ }^{3}$.

\subsection{A abordagem das elasticidades}

Para este primeiro enfoque, na ausência de outros choques, as elasticidades-preço relativas de oferta e demanda dos bens comerciáveis são os determinantes principais do pass-through. No caso dos bens exportados, o grau de pass-through aumentará quanto maior for a elasticidade preço de demanda e menor for a elasticidade preço de oferta. Especificamente, quando os exportadores enfrentam uma curva de demanda perfeitamente elástica, uma mudança na taxa de câmbio não desvia o preço das exportações em moeda doméstica com respeito ao preço estrangeiro, quando expresso numa moeda comum. Para isso, é necessário que o preço em moeda doméstica das exportações mova-se na exata proporção da taxa de câmbio de forma que o pass-through é completo.

Mais formalmente, pode-se definir:

$$
\begin{gathered}
\eta_{x}=-\frac{q_{x}}{p_{x}^{*}} \\
\tau_{x}=\frac{q_{x}}{p_{x}}
\end{gathered}
$$

onde $x$ : exportações; $q$ : taxa de variação da quantidade; $p$ : taxa de variação do preço doméstico; $p^{*}=$ taxa de variação do preço no resto do mundo; $\eta_{x}=$ elasticidade-preço da demanda por exportações; e $\tau_{x}$ = elasticidade-preço da oferta de exportações.

Adicionalmente, define-se:

$p_{x}=e+p_{x}^{*}$

onde $e$ representa a variação na taxa de câmbio,medida em unidades da moeda doméstica por unidade de moeda estrangeira.

A Equação (1) pode ser reescrita como:

$$
q_{x}=-\eta_{x} p_{x}^{*}
$$

${ }^{3}$ Esta seção baseia-se em Menon (1995) e Ferreira (2000). 
Substituindo as Equações (3) e (4) na Equação (2), obtém-se:

$$
\begin{aligned}
& \tau_{x}=\frac{-\eta_{x} p_{x}^{*}}{e+p_{x}^{*}} \\
& \text { Isolando } p_{x}^{*}, \text { obtém-se: } \\
& p_{x}^{*}=\left[\frac{-\tau_{x}}{\eta_{x}+\tau_{x}}\right] e
\end{aligned}
$$

A Equação (5) mostra que o impacto das variações na taxa de câmbio sobre o preço das exportações $\left(p_{x}^{*}\right)$ é dado pela expressão entre colchetes. Assim, o coeficiente de pass-through será nulo (isto é, variações na taxa de câmbio não afetarão o preço dos produtos exportados no mercado externo), caso uma das seguintes condições se verifique: (i) a elasticidade-preço da oferta de exportações seja igual a zero $\left(\tau_{x}=0\right)$ ou (ii) a elasticidadepreço da demanda de exportações seja infinita $\left(\eta_{x}=\infty\right)$. No entanto, o coeficiente de pass-through será igual a -1, e o pass-through, portanto, será completo se: (iii) a elasticidade-preço da demanda de exportações for zero $\left(\eta_{x}=0\right)$, (iv) a elasticidade-preço da oferta de exportações for infinita $\left(\tau_{x}\right.$ $=\infty$ ). Entre os casos extremos descritos, várias situações de pass-through não-nulo, porém incompleto, podem ocorrer.

Existem vários problemas associados à medida do pass-through baseada unicamente nas elasticidades da oferta e da demanda. Primeiro, essa abordagem não fornece qualquer informação sobre o timing da resposta dos preços às mudanças na taxa de câmbio. Segundo, ignora o que está por trás da resposta das empresas exportadoras em diferentes países. A resposta das empresas exportadoras depende de questões de organização industrial e de tecnologia da indústria sob estudo. ${ }^{4}$

\subsection{Recentes desenvolvimentos}

A seguir são apresentados os mais recentes desenvolvimentos que enfatizam: i) a estrutura de mercado e as características dos produtos; ii) o papel da empresas multinacionais e do comércio intrafirma; e iii) os efeitos das bareiras não-tarifárias.

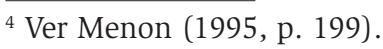




\subsubsection{Estrutura de mercado e características dos produtos}

As explicações teóricas do pass-through incompleto têm enfatizado o papel da estrutura de mercado, em primeiro lugar, e depois a diferenciação do produto.

Menon (1995, p.199-200) mostra que, assumindo um mercado perfeitamente competitivo onde o produto importado e o domesticamente produzido são substitutos perfeitos, a medida do pass-through equivale a usar a abordagem das elasticidades apresentada anteriormente. Levantar tais pressupostos implica diferentes medidas do pass-through.

Por exemplo, sob condições de concorrência imperfeita, as regras de fixação de preços não serão mais feitas com base no custo marginal, e as firmas estarão na posição de fixar um markup sobre os custos. Nesse caso, é necessário analisar como esse markup acima do custo marginal varia em resposta a uma mudança na taxa de câmbio. A literatura tem proposto dois fatores. O primeiro relaciona-se com o grau de substituição entre o bem importado e o bem doméstico, como determinado pelo grau de diferenciação do produto. O segundo, com o grau de integração ou separação do mercado. Ambos os fatores determinam o poder de fixação de preços das empresas, e afetam suas decisões de resposta face às mudanças na taxa de câmbio. Quanto menor for o grau de substituição entre esses bens e quanto menor for o grau de integração de mercado, maior será o poder de mercado dos vendedores.

Por exemplo, Dornbusch (1987) desenvolve um modelo de concorrência em círculo para capturar o efeito da substituição imperfeita e da diferenciação do produto sobre a resposta dos preços face a uma mudança na taxa de câmbio. Ele conclui que o grau de pass-through está diretamente relacionado ao grau de substituição entre o bem doméstico e o bem importado. Fischer (1989) considera o caso no qual as firmas são concorrentes do tipo Bertrand e as empresas estrangeiras produzem para o mercado doméstico e o estrangeiro, mas não praticam discriminação de preços. Ele mostra que se os mercados são segmentados, de forma que a arbitragem é limitada, uma apreciação levará a um maior pass-through se o mercado doméstico for monopolístico em relação ao mercado externo. ${ }^{5}$ Usualmente, os bens manufaturados são vistos como

${ }^{5}$ Existem outras várias razões de por que os mercados nacionais (ou regionais) poderiam 
altamente diferenciados e freqüentemente vendidos em mercados imperfeitamente competitivos e segmentados, nos quais a arbitragem é custosa e normalmente gera prejuízo. A evidência empírica confirma essa hipótese. ${ }^{6}$ Outra linha de pesquisa iniciada com os estudos de Baldwin (1988), Dixit (1989) e Krugman (1989) desenvolve modelos de histerese de fixação de preços. Essa linha baseia-se na noção de sunk costs irrecuperáveis associados às decisões de entrada e saída nos mercados mundiais. Existem custos afundados de entrar em um mercado que as firmas não podem recuperar quando elas o deixam. O efeito de histerese sugere que a concorrência no mercado permanecerá invariável, na medida em que as mudanças da taxa de câmbio flutuem dentro de uma banda e que essa banda seja maior do que os custos associados com a entrada e saída. Isso resultará em um menor grau de pass-through, uma vez que as empresas lutaram para entrar no mercado ou preferiram permanecer nele.

\subsubsection{Empresas multinacionais e comércio intra-indústria}

A grande instabilidade presente nos mercados cambiais e, em particular, os grandes movimentos cambiais que caracterizam os regimes de taxas de câmbio flutuantes têm induzido as empresas multinacionais a empregar ativamente políticas de fixação de preços que impeçam, ou ao menos reduzam, a transmissão completa das mudanças na taxa de câmbio para os preços de venda em mercados individuais. Essa prática tem facilitado a estabilização dos preços nos mercados domésticos, e permitido que as subsidiárias das empresas multinacionais evitem as perdas significativas das parcelas de mercado que se seguem às grandes depreciações cambiais.

\subsubsection{Barreiras não-tarifárias}

O papel das barreiras não-tarifárias na determinação do grau do passthrough também tem sido levantado. Mostra-se, por exemplo, que depre-

estar segmentados, com escopo, portanto, para discriminação de preços: (i) custos de transporte, (ii) impostos alfandegários, (iii) barreiras não-tarifárias, (iv) diferenças físicas nas características dos produtos e (v) fidelidade dos consumidores à marca ou ao país.

${ }^{6}$ Ver Menon (1995, p. 201). 
ciações da taxa de câmbio na presença de restrições às importações geralmente reduzem primeiro o markup do importador, absorvendo, portanto, muito do seu impacto antes que a depreciação seja refletida nos preços. Somente quando a depreciação é suficientemente grande para empurrar os preços até o ponto no qual as restrições quantitativas não cumprem mais seu papel restritivo é que se observará algum grau de pass-through.

\subsection{Alguns problemas relativos à agregação e ao pass-through variável no tempo.}

A seguir, são apresentados alguns problemas que podem surgir na análise do pass-through. Alguns estudos sugerem que, após um movimento da taxa de câmbio, pode ocorrer uma ampla gama de resultados relacionados à indústria. As diferentes indústrias agregam-se na economia completa, mas essa agregação levanta dificuldades. Entre outras críticas aos estudos que usam índices de preços agregados para o passthrough, podem ser assinaladas: (i) erros de medida; (ii) mudanças na composição dos bens; (iii) efeitos de terceiros países; e (iv) problema da simultaneidade. ${ }^{7}$ Portanto, espera-se que exista variação no que concerne às indústrias no grau de pass-through.

Em adição à agregação, existem outras razões para esperar uma variação ao longo do tempo nos parâmetros da relação do pass-through. Nos últimos anos, muitos países deixaram de usar regimes de taxa de câmbio fixa ou semi-fixa e passaram a usar câmbio flutuante. Adicionalmente, ocorreram mudanças no ambiente inflacionário de diferentes países. Espera-se que esses fatores mudem a magnitude do pass-through.

Uma questão crucial é a dinâmica em sua relação com o horizonte temporal do pass-through da taxa de câmbio. A maior parte da pesquisa está concentrada no efeito dos preços sobre um horizonte relativamente curto. Dois pontos, porém, devem ser comentados.

Primeiro, o pass-through das mudanças da taxa de câmbio depende de a mudança ser percebida como transitória ou permanente. Um choque transitório de taxa de câmbio terá pouco ou nenhum efeito sobre os preços. Mudanças futuras na taxa de câmbio são determinantes cruciais

\footnotetext{
${ }^{7}$ Ver Darvas (2001).
} 
do pass-through da taxa de câmbio e fornecem um simples modelo em que o coeficiente de pass-through varia ao longo do tempo, isto é, é uma função da taxa de câmbio futura esperada. Segundo, a questão de se a taxa de câmbio real flutua ou não é de fundamental importância aqui. Desvios da Paridade do Poder de Compra (PPP) podem ser explicados parcialmente por pass-through imperfeito e pricing to market. Inversamente, um pass-through perfeito para os preços dos consumidores implicaria uma taxa de câmbio real constante. No entanto, as taxas de câmbio podem mudar de um segundo para outro, enquanto os preços dos produtos mudam menos freqüentemente, o que significa que a taxa de câmbio real não pode ser constante. Ao invés disso, a não-flutuação da taxa de câmbio real poderia implicar pass-through completo.

\subsection{O pass-through para os preços das exportações}

Muitos trabalhos que tentam medir o pass-through utilizam um modelo de markup. A seguir, apresentamos o modelo desenvolvido por Ferreira $(2000)^{8}$. Ele assume que os exportadores estabelecem o preço das exportações na moeda estrangeira $\left(P_{x}^{*}\right)$ como um markup $(\lambda)$ acima de seu custo de produção na moeda estrangeira $(C P / E)$ da seguinte forma:

$$
P_{x}^{*}=(1+\lambda)(C P / E)
$$

onde $C P=$ custo de produção na moeda doméstica; $E=$ taxa de câmbio nominal; e $\lambda=$ markup. Assume-se que o markup pode variar de acordo com a pressão competitiva no mercado mundial. Usa-se como proxy da pressão competitiva o gap entre o preço das exportações mundiais $\left(P_{w}\right)$ e o custo de produção do exportador, medido na moeda estrangeira $(C P / E)$, isto é:

$$
(1+\lambda)=\left[\frac{P_{w}}{(C P / E)}\right]^{\alpha}
$$

Combinando as Equações (6) e (7), então, obtém-se:

$$
\ln P_{x}^{*}=(1-\alpha) \ln (C P / E)+\alpha \ln P_{w}
$$

\footnotetext{
${ }^{8}$ Baseado em Menon (1995).
} 
Postulando uma versão não restrita da Equação (8), na qual não se exija que a soma dos coeficientes relativos a $\ln (C P / E)$ e $\ln P_{w}$ seja igual a 1 e na qual se admita que os coeficientes relativos a ln $(C P / E)$ e $\ln P_{w}$ difiram em sinal e magnitude, ou seja:

$$
\ln P_{x}^{*}=\phi_{0}+\phi_{1} \ln C P+\phi_{2} \ln E+\phi_{3} \ln P_{w}
$$

O coeficiente de pass-through é medido pelo parâmetro $\phi_{2}$. Quando $\phi_{2}$ $=0$, o pass-throug é nulo e a taxa de câmbio não tem qualquer influência sobre o preço em moeda estrangeira dos bens exportados; portanto, mudanças cambiais afetam apenas as margens de lucro dos exportadores, sem ter impacto sobre a "competitividade" das exportações nacionais. Quando $\phi_{2}=-1$, o pass-through é completo, e quaisquer mudanças na taxa de câmbio são transmitidas integralmente para o preço em moeda estrangeira dos produtos exportados, afetando, assim, a competitividade da produção doméstica no mercado mundial. Obviamente, para valores $-1<\phi_{2}<0$, o pass-through será incompleto. A relação de pass-through entre mudanças na taxa de câmbio e preços dos bens exportados determina o grau de competitividade alcançado a partir de variações na taxa de câmbio. A eficácia da taxa de câmbio, como instrumento de política em programas de promoção de exportações e ajustamento da conta corrente do balanço de pagamento, depende, portanto, do coeficiente de pass-through.

\section{Estudos empíricos}

De acordo com a literatura econômica sobre o pass-through da taxa de câmbio, os estudos empíricos analisam os efeitos das mudanças das taxas de câmbio sobre um dos seguintes itens: (1) preços aos consumidores; ${ }^{9}$ (2) investimentos; ${ }^{10}$ (3) volumes de comércio e (4) preços das importações ${ }^{11}$ e das exportações.

\footnotetext{
${ }^{9}$ Ver por exemplo, Dornbusch (1987), que foi o primeiro a avançar e testar um modelo teórico do pass-through de depreciação para a inflação. Ver tambem Goldfjan e Werlang (1999). ${ }^{10}$ Ver, por exemplo, Campa e Goldberg (1998).

${ }^{11}$ Diversos estudos, revisados em Menon (1995) e Goldberg e Knetter (1997), reportam a um consenso bastante bem sustentado para um pass-through incompleto de $60 \%$ para os preços das importações dos EUA, embora existam diferenças importantes, dependendo do produto analisado. Dwyer et al. (1993) têm estimado a dinâmica do pass-through da taxa de câmbio para os preços dos produtos importados pela Austrália e mostrado que
} 
A seguir, revisamos os principais estudos sobre o pass-through da taxa de câmbio para os preços das exportações. Dwyer et al. (1993) têm estimado a dinâmica do pass-through da taxa de câmbio para os preços das importações e os produtos manufaturados exportados da Austrália. Os referidos autores mostram que a longo-prazo, o pass-through é completo. No entanto, existe um padrão muito defasado de resposta, ao longo do tempo, às mudanças na taxa de câmbio.

Wang e Wu (1996) investigaram o pass-through em uma indústria exportadora especial, a indústria petroquímica de Taiwan. Tal indústria é caracterizada por um alto poder monopólico e fraca concorrência nos países de destino de suas exportações. Eles mostram que nem todas as indústrias de Taiwan respondem da mesma forma às mudanças da taxa de câmbio.

Goldberg e Knetter (1997) sugerem que o pass-through da taxa de câmbio deve-se à discriminação de preços de terceiro grau. Assim, enquanto a distância é um fator importante para a segmentação do mercado, as fronteiras têm efeitos independentes. No entanto, a fonte desse efeito fronteira ainda não foi identificada.

Existe relativamente pouco trabalho empírico sobre o Brasil, no caso do pass-through das mudanças da taxa de câmbio para os preços das exportações. Os principais trabalhos são os de Ferreira e Sanso (1999), Kannebley (2000) e Ferreira (2000).

Ferreira e Sanso (1999) analisaram o pass-through da taxa de câmbio para as exportações brasileiras de produtos manufaturados, no período 1978:3 a1996:4. As estimativas do coeficiente do pass-through, derivadas usando testes de co-integração baseados nos procedimentos de Engle-Granger, Shin e Johansen, e diferentes especificações do modelo, ficam num intervalo relativamente estreito de $10 \%$ a $27 \%$.

Kannebley (2000) realizou um estudo sobre o pass-through da taxa de câmbio para as exportações brasileiras no período 1984 a 1997. Para tanto, usou uma análise de séries de tempo combinada à estimação de modelos lineares seguindo uma metodologia de modelagem econométrica

existe um padrão consistente de resposta bastante rápida ao longo do tempo. Coughlin e Pollard (2000) têm estudado o pass-through das mudanças da taxa de câmbio para os preços das importações do setor manufatureiro dos Estados Unidos. Um aspecto interessante é a análise do papel da escolha de um índice de taxa de câmbio apropriado, mostrando que as estimativas do coeficiente de pass-through são muito sensíveis à escolha do índice. Quanto mais abrangente o índice utilizado, maior o coeficiente de pass-through. 
geral-to-specific. Seus resultados apontam para a existência de um grau de pass-through nulo ou incompleto para os nove setores analisados (Extrativa Mineral; Siderurgia; Metais não-ferrosos; Máquinas e Tratores; Veículos Automotores; Peças e outros Veículos; Madeira e Mobiliário; Celulose, Papel e Gráfica e Óleos Vegetais).

Ferreira (2000), usando a equação (10) e a análise de co-integração, estimou um coeficiente de pass-through relativamente baixo, $\phi_{2}=0,27$, isto é, $27 \%$. Isso reflete o fato de que países como o Brasil têm pouco controle sobre os preços pelos quais efetuam vendas nos mercados externos. A implicação é que mudanças na taxa de câmbio podem ter pouca relevância na determinação dos preços de suas exportações naqueles mercados, isto é, o coeficiente de pass-through pode ser próximo a 0. Também implica que a desvalorização da taxa de câmbio tenha efeito limitado sobre a demanda de exportações.

\section{Estimação do modelo e análise de resultados}

Os setores analisados, assim como suas respectivas participações na pauta de exportações no ano de 2004, são: Peças e Outros Veículos PEOV (10,29\%), Siderurgia - SID (7,11\%), Extrativa Mineral (8,41\%), Máquinas e Tratores - MAQ (5,33\%), Veículos Automotores - VAUT (5,05\%), Óleos Vegetais - OVEG (4,96\%), Refino de Petróleo - PET (4,55\%), Madeira e Mobiliário - MAD (4,14\%), Beneficiamento de Produtos Vegetais - BVEG (3,22\%), Metalurgia de Não-ferrosos - MNF $(3,16 \%)$, Celulose Papel e Gráfica - PAP (3,06\%), Material Elétrico ELET (2,34\%), Elementos Químicos - QUIM (2,15\%), e Equipamentos Eletrônicos - EQP (2,10\%). Esses setores juntos representaram 65,86\% das exportações totais brasileiras, no ano de 2004. Para propósitos de comparação, foram analisadas também as exportações totais.

Como discutido na parte teórica deste artigo, existe a possibilidade de que o coeficiente de pass-through seja variável no tempo, portanto estima-se a Equação (9), permitindo que tal coeficiente possua tal comportamento. Assim, a Equação (9) passa a ter a seguinte forma ${ }^{12}$ :

${ }^{12}$ Inicialmente, seguiu-se uma metodologia desenvolvida por Kim (1990), em que se permite que todos os coeficientes da equação (11) sejam variáveis no tempo. Como os melhores resultados obtidos foram aceitando que somente seja variável no tempo o coeficiente de pass-through, são apresentados os dados relativos a essa formulação do modelo. 


$$
\ln P_{x}^{*}=\phi_{0}+\phi_{1} \ln C P+\phi_{2} \ln P_{w}+\phi_{t} \ln E+u_{t}
$$

onde $\phi_{t}$ é o coeficiente de pass-through variável no tempo e $P_{x}^{*}=$ preço das exportações em moeda estrangeira (medido pela série dos preços de exportação de cada um dos setores analisados); $C P=$ custo de produção na moeda doméstica (medido pelo Índice de Preços por Atacado - Disponibilidade Interna da FGV); $E$ = taxa de câmbio nominal (medida pela taxa de câmbio nominal real/dólar) e $P_{w}=$ preço das exportações mundiais. Todas as séries de dados foram obtidas por meio do Ipeadata.

Também assume-se que $\phi_{t}$ segue um passeio aleatório sem drift:

$\phi_{t}=\phi_{t}+v_{t}$

onde $v_{t}$ é um ruído branco. Na Equação (11), o processo é não estacionário e permite, assim, acomodar mudanças fundamentais na estrutura (ver Harvey, 1981, p. 204). Obviamente, poderia se utilizar uma evolução dinâmica mais complexa de $\phi_{t}$, no entanto, na ausência de estimativas a priori, esse modelo mostra ser um bom ponto de partida.

O sistema de Equações (10) e(11) toma a forma de um modelo espaço-estado. Para a estimação, utiliza-se o filtro de Kalman. Embora existam outros métodos para estimar modelos com parâmetros variáveis no tempo, justifica-se a escolha do filtro de Kalman por ser superior para a estimação de tais modelos ${ }^{13}$. A aplicação do filtro de Kalman gera duas séries de estimativas dos coeficientes variáveis no tempo. A primeira, chamada de filtrada, origina-se da estimação recursiva do modelo, usando dados que estão somente disponíveis até o período corrente; em cada período, o filtro usa a nova informação para revisar suas estimativas dos parâmetros do modelo e as estimativas dos coeficientes variáveis no tempo. A segunda, chamada de suavizada, usa os dados da amostra completa para estimar a série temporal dos coeficientes variáveis no tempo, o que permite avaliar de forma retrospectiva se as estimativas recursivas (filtradas) produzem uma trajetória diferente dos coeficientes variáveis no tempo, quando se usa a amostra completa (toda a informação).

O sistema de Equações (10) e(11) foi estimado usando dados trimestrais no período 1980.1 a 2004.1. Todas as variáveis passaram por um processo de ajuste sazonal. Na Tabela A do Apêndice, são mostrados os resultados das estimações da Equação (10) para os setores analisados.

${ }^{13}$ Ver Judge et al.(1985, cap. 19) e Portugal (1993). 
Em todas as equações as variáveis encontram-se em logaritmo. São mostrados os melhores resultados obtidos para cada um dos setores. Pode-se observar que em todas as equações estimadas, os coeficientes fixos possuem os sinais esperados e são estatisticamente significativos em um nível de confiança de $5 \%$. A seguir, mostram-se as trajetórias temporais de cada um dos coeficientes variáveis no tempo, estimados para cada setor e para as exportações totais.

O Gráfico 1 mostra o coeficiente estimado variável no tempo de passthrough da taxa de câmbio para as exportações totais brasileiras (o coeficiente de pass-through é chamado PT_SM, em todas as figuras apresentadas de agora em diante). Como uma estimativa mais precisa do coeficiente de pass-through é dada pela série suavizada, uma vez que usa toda a informação disponível, apenas mostramos a trajetória temporal da série suavizada. Como era esperado, o sinal é negativo ao longo de todo o período. Observa-se que o pass-through se mantém em torno de $18 \%$ até 1991. Após 1991, o pass-through aumenta até atingir $22 \%$ no início de 1993. Após esse período, reduz-se bastante até o final de 1998, quando atinge $13 \%$. Após 1999, há um aumento no pass-through que passa a oscilar em torno de $17 \%$. Para comparação, pode-se mencionar que o coeficiente de pass-through - estimado como um parâmetro fixo encontrado por Ferreira (2000) para as exportações totais foi de $27 \%$.

São mostrados também os intervalos de confiança das estimativas (linhas cinzas tracejadas).

Os Gráficos 2 a 15 expõem os coeficientes estimados variáveis no tempo do pass-through da taxa de câmbio para os preços das exportações dos setores. Em todos os casos, como era esperado teoricamente, o sinal é negativo, ao longo de todo o período. No entanto, observam-se diferenças de setor a setor.

No caso dos setores Madeira e Mobiliários (Gráfico 8) e Equipamentos e Eletrônicos (Gráfico 11), há uma clara tendência de redução do coeficiente de pass-through, ao longo do período. Comparando as médias das estimativas por sub-períodos, pode-se observar que ela diminui, passando de -0,20, no período 1980.1 a 1994.2, para -0,16, no período 1991./2004.1 (ver Tabela B do Apêndice), no caso do setor de Madeira e Mobiliários, e de -0,19 para -0,14, nos mesmos subperíodos, no caso do setor Equipamentos e Eletrônicos. 
Gráfico 1. Estimativa variável no tempo do pass-through da taxa de câmbio para as exportações totais no período 1980:1 a 2004:1

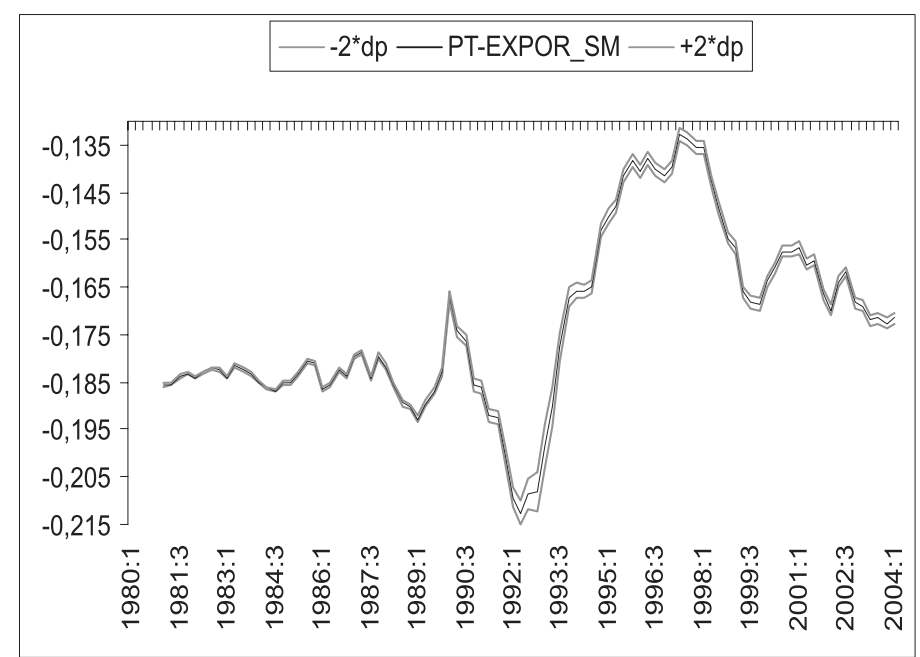

Gráfico 2. Celulose, papel e gráfica

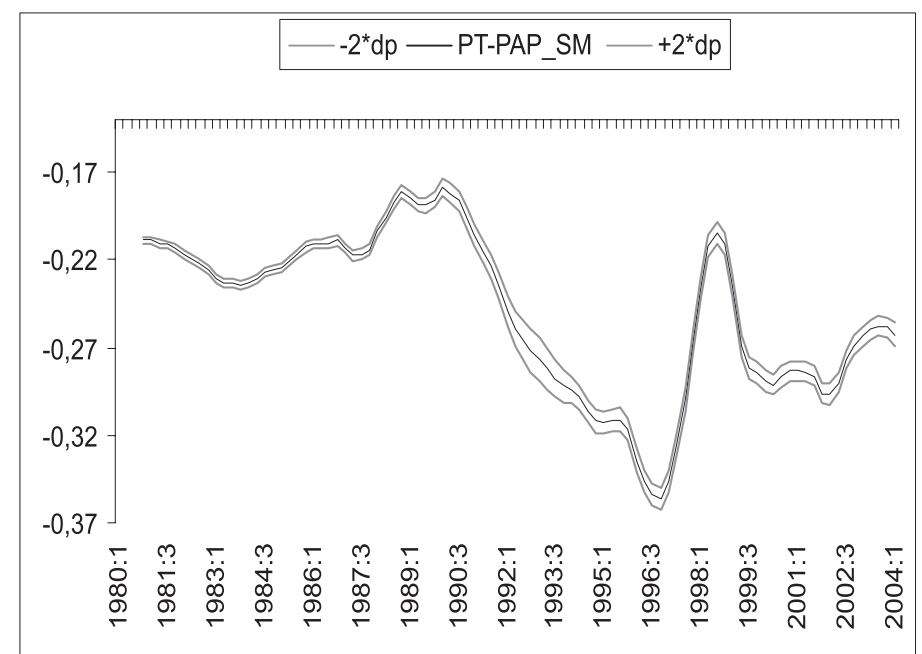

RER, Rio de Janeiro, vol. 46, no 01, p. 171-205, jan/mar 2008 - Impressa em abril 2008 
Gráfico 3. Elementos químicos

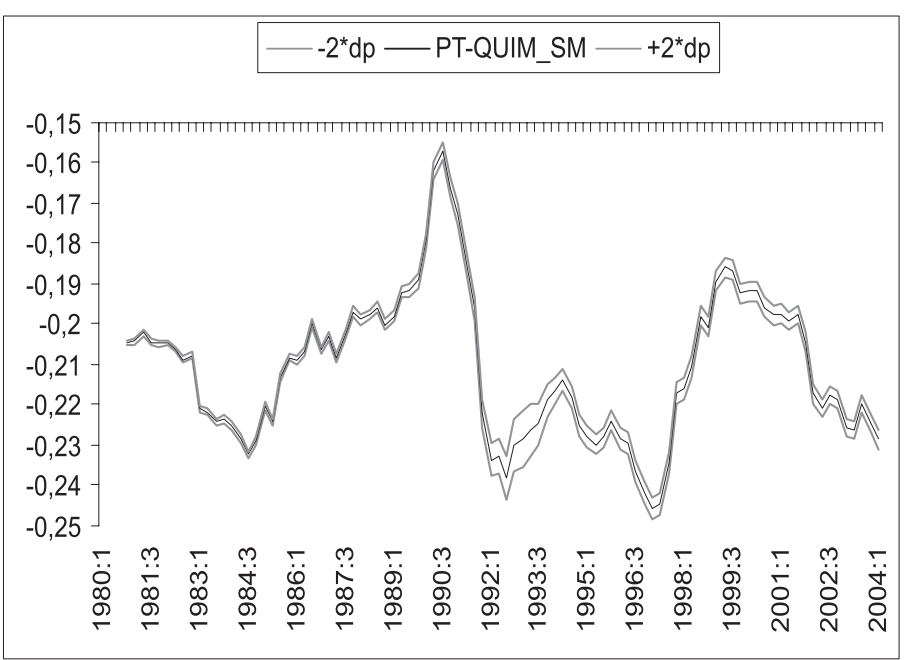

Gráfico 4. Peças e outros veículos

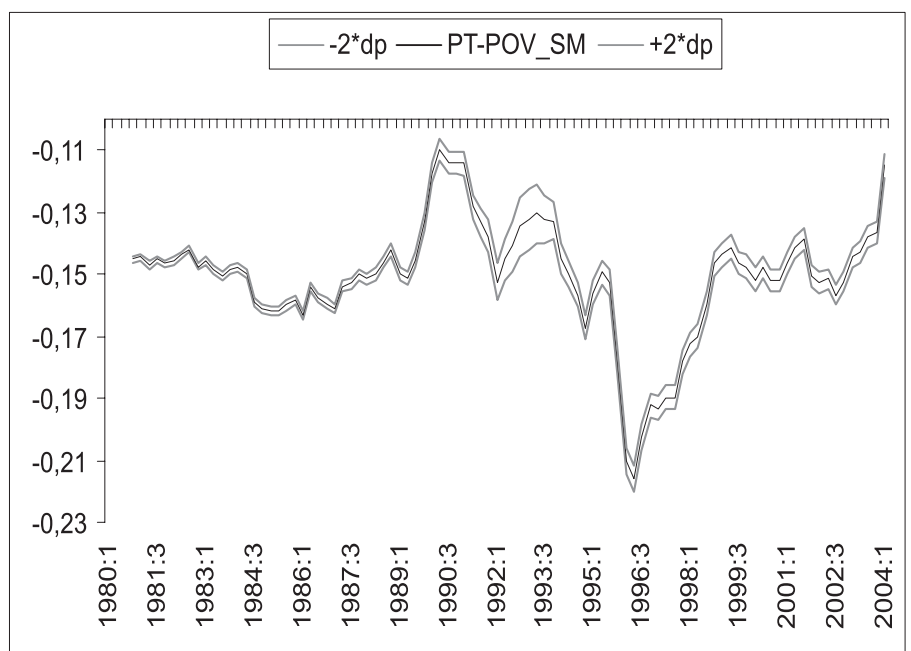

RER, Rio de Janeiro, vol. 46, no 01, p. 171-205, jan/mar 2008 - Impressa em abril 2008 
Gráfico 5. Refino de petróleo

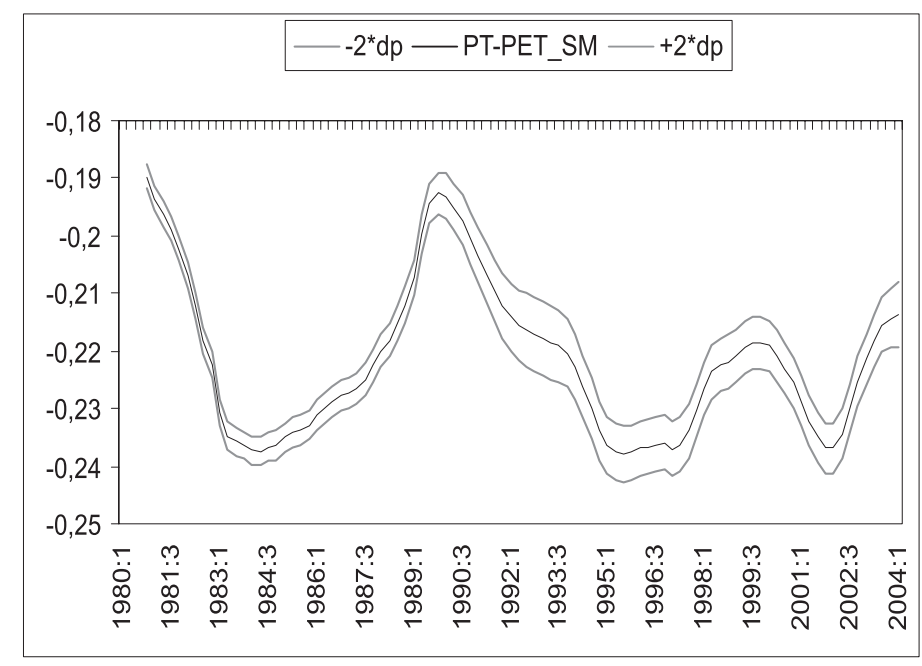

Gráfico 6. Óleos vegetais

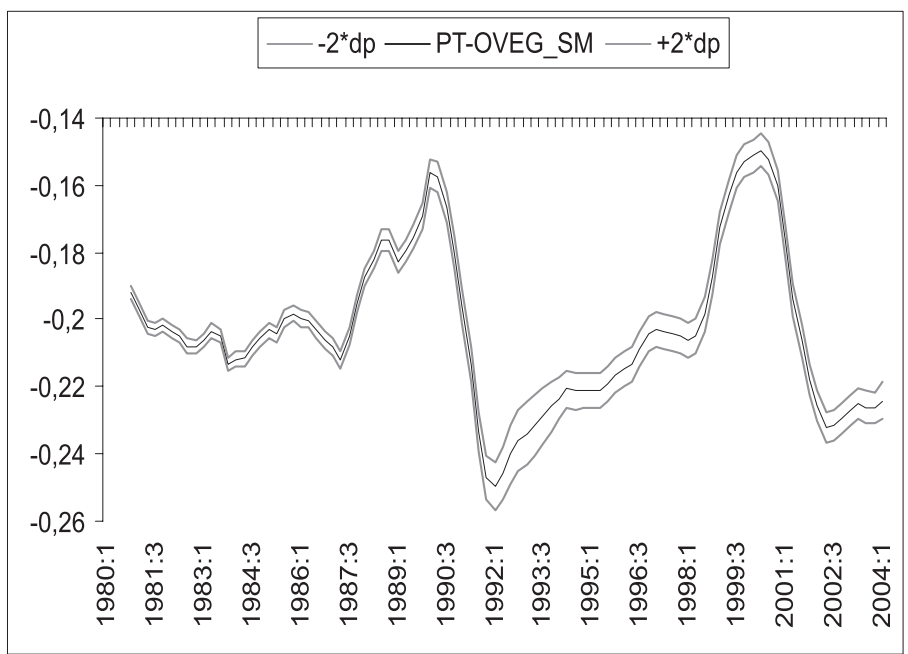

RER, Rio de Janeiro, vol. 46, oㅡ 01, p. 171-205, jan/mar 2008 - Impressa em abril 2008 
Gráfico 7. Máquina e tratores

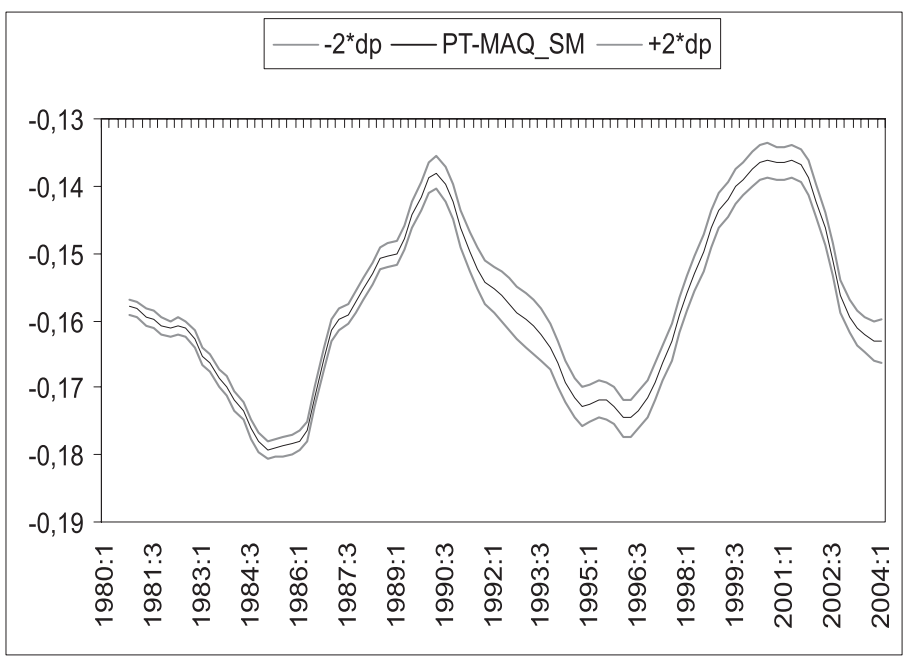

Gráfico 8. Madeira e mobiliário

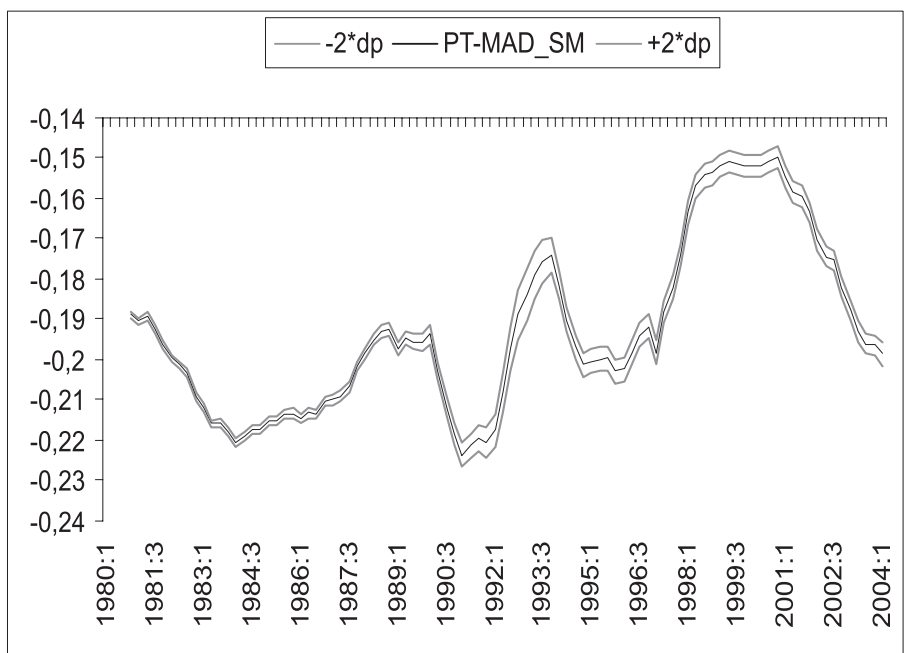

RER, Rio de Janeiro, vol. 46, no 01, p. 171-205, jan/mar 2008 - Impressa em abril 2008 
Gráfico 9. Extrativa mineral

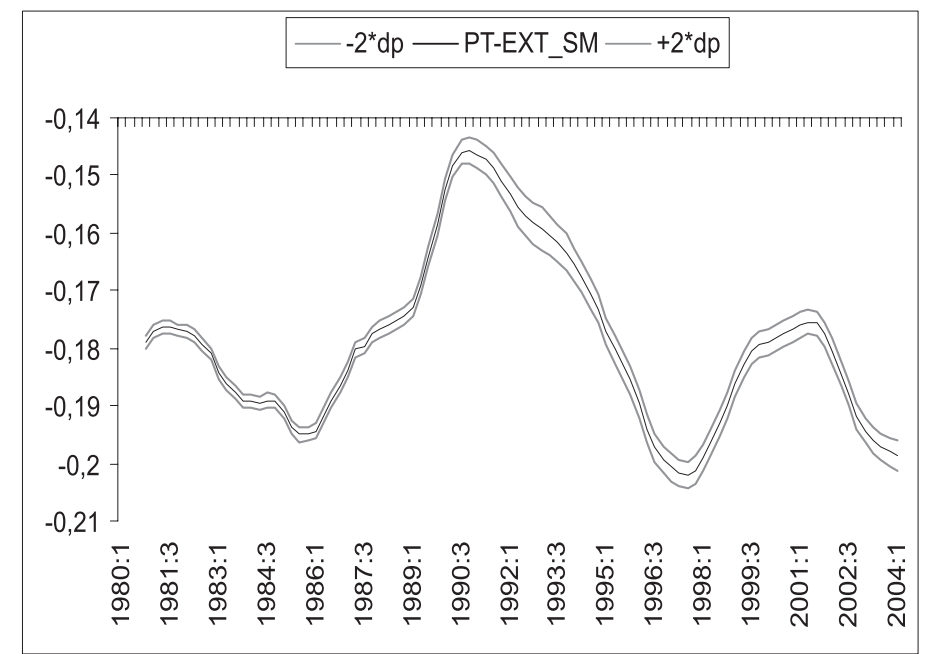

Gráfico 10 . Metalurgia não-ferrosos

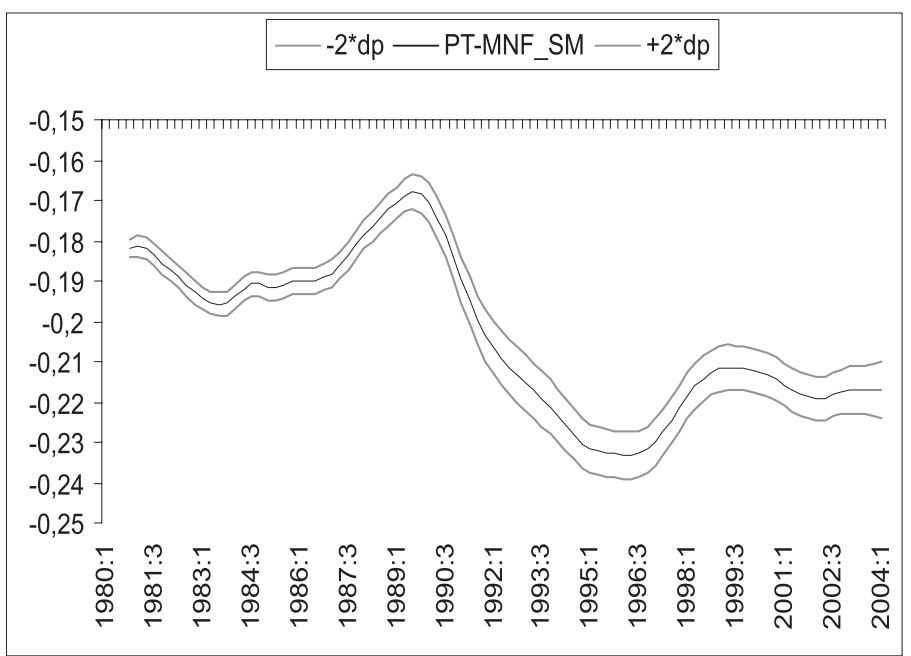

RER, Rio de Janeiro, vol. 46, oㅡ 01, p. 171-205, jan/mar 2008 - Impressa em abril 2008 
Gráfico 11. Equipamentos eletrônicos

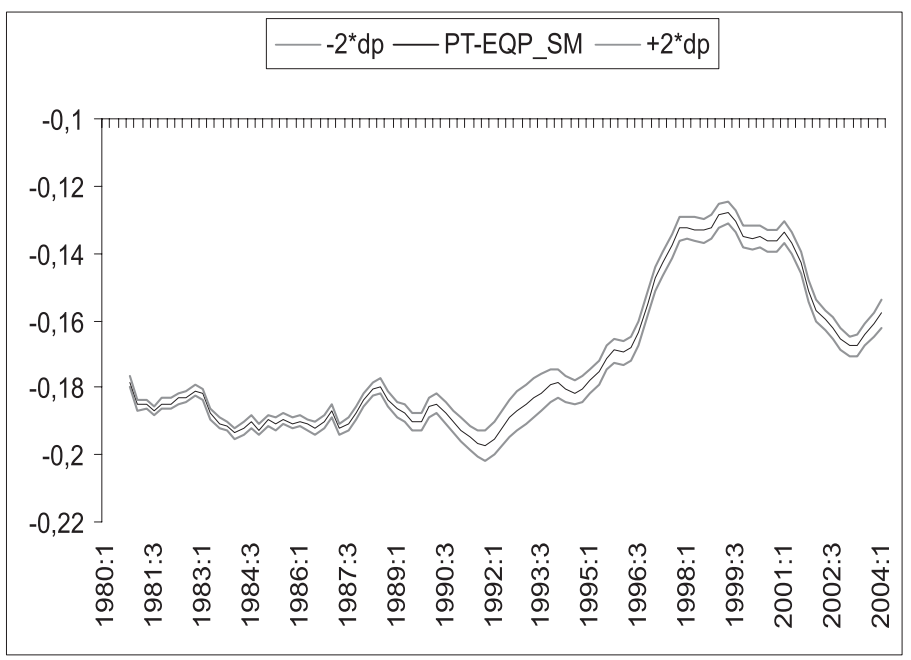

Gráfico 12. Material elétrico

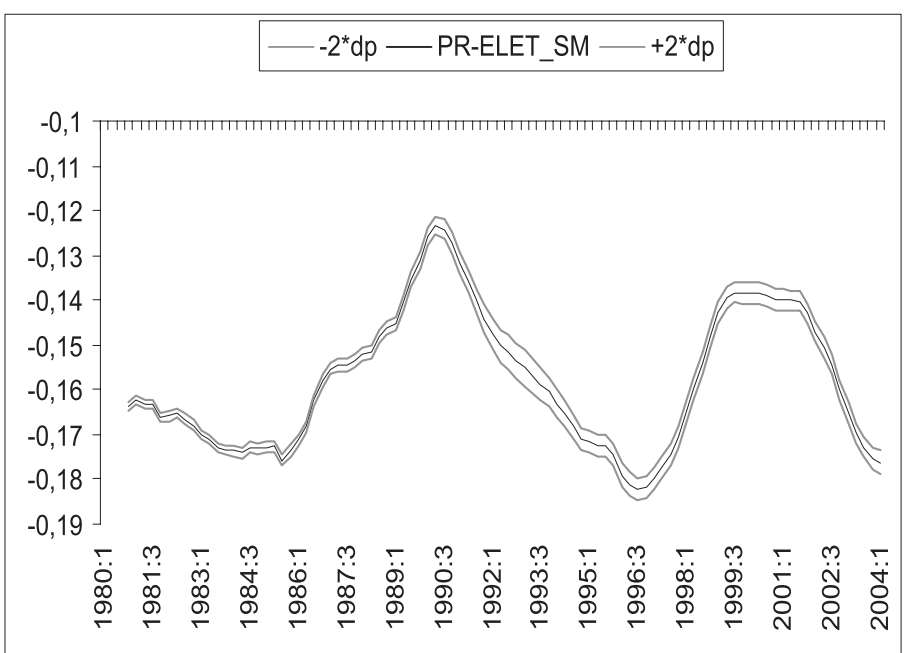

RER, Rio de Janeiro, vol. 46, no 01, p. 171-205, jan/mar 2008 - Impressa em abril 2008 
Gráfico 13. Beneficiamento de produtos vegetais

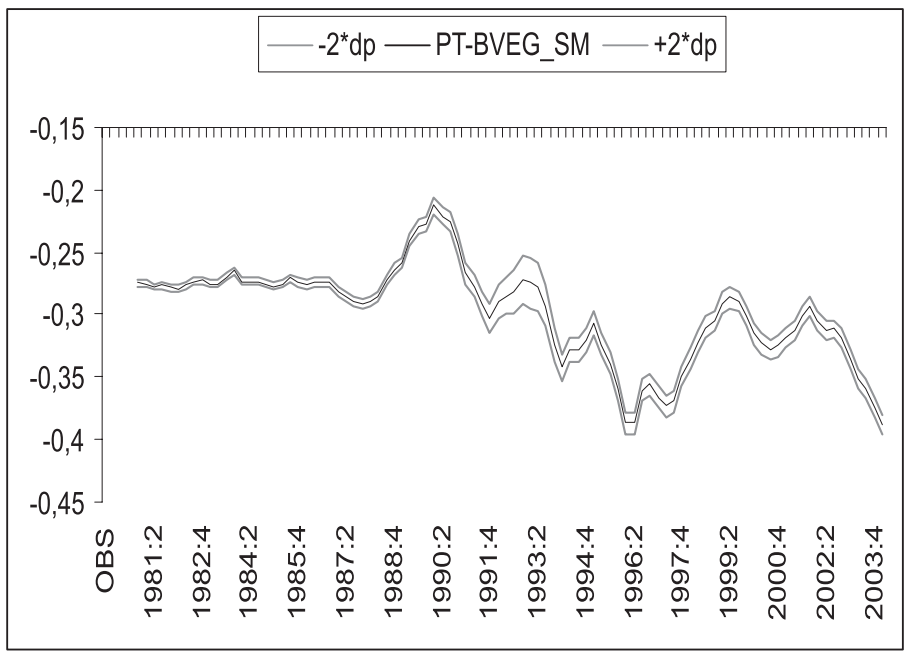

Gráfico 14. Veículo automotores

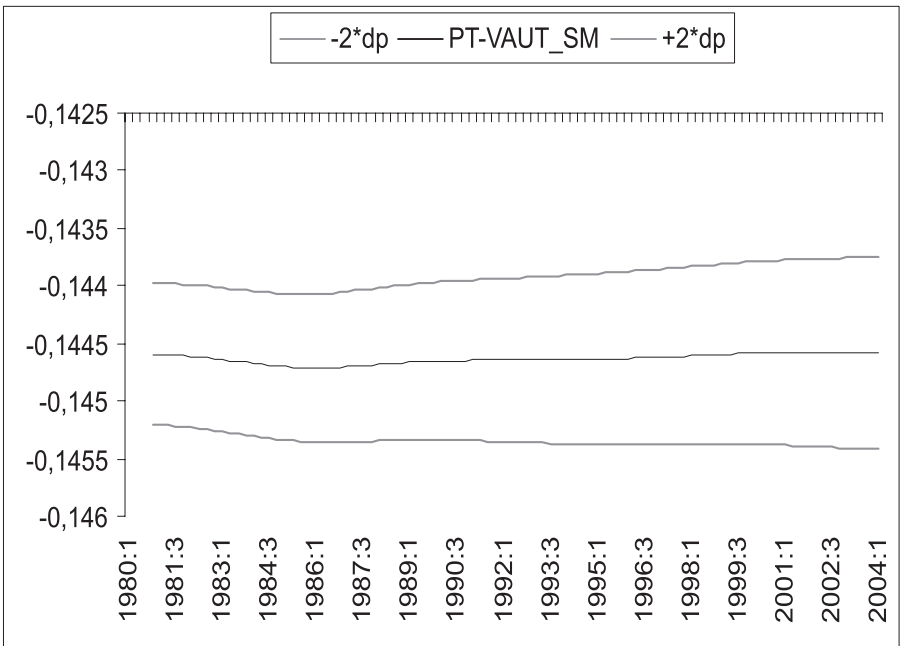

RER, Rio de Janeiro, vol. 46, oㅡ 01, p. 171-205, jan/mar 2008 - Impressa em abril 2008 
Gráfico 15. Siderurgia

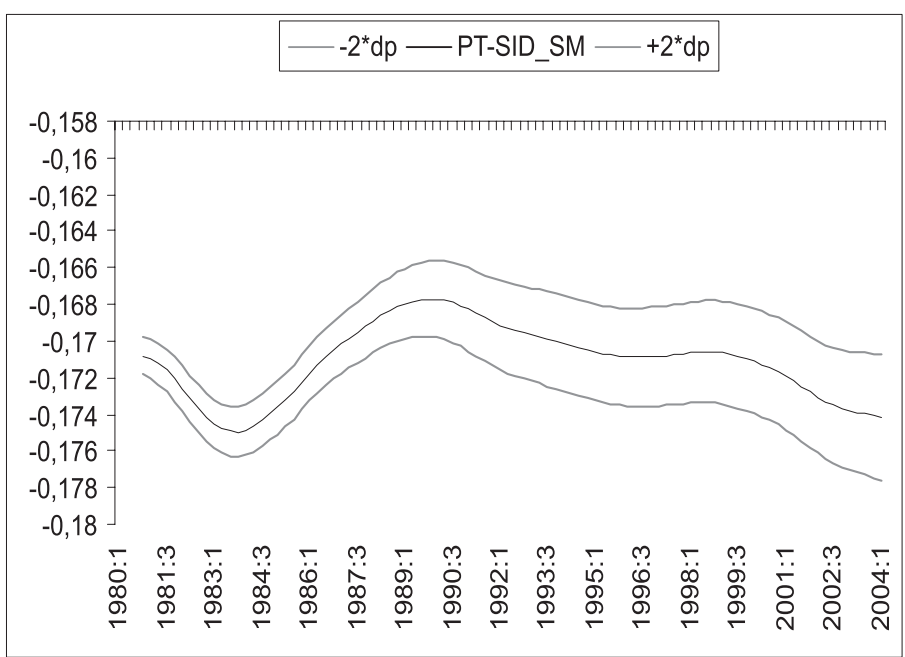

No caso dos setores Celulose, Papel e Gráfica (Gráfico 2), Metalurgia Não-ferrosos (Gráfico 10) e Beneficiamento de Produtos Vegetais (Gráfico 13), há uma clara tendência de aumento do coeficiente de passthrough ao longo do período. Comparando as médias das estimativas por sub-períodos, pode-se observar que ela aumenta de $-0,22$, no período 1980.1 a 1994.2, para -0,27, no período 1991 a 2004.1 (ver Tabela B do Apêndice); no caso do setor de Celulose, Papel e Gráfica, e de -0,27 para -0,32, nos mesmos sub-períodos, no caso do setor Beneficiamento de Produtos Vegetais.

No caso dos setores Veículos Automotores (Gráfico 14) e Siderurgia (Gráfico 15), as estimativas do coeficiente de pass-through são praticamente constantes ao longo do período. Nos demais setores existe alguma variabilidade nas estimativas dos coeficientes de pass-through, mas não há um padrão definido.

Outro resultado importante é que os coeficientes estimados são relativamente baixos. Pode-se observar na Tabela B do Apêndice, considerando-se todos os setores, que o menor coeficiente médio obtido foi de $-0,14$ e o máximo foi de $-0,34$.

É importante destacar algumas das explicações para esses baixos coeficientes. A primeira, segundo Lopes (1988) e Pereira \& Carvalho 
(2000), está relacionada ao desmonte dos mecanismos de indexação na economia brasileira pois, na presença desses, qualquer variação de preços relativos poderia significar uma mudança direta nos preços finais da economia. Assim, a desindexação da economia brasileira, a partir do Plano Real em julho de 1994, mudou significativamente a dinâmica entre preço e câmbio. Tal fato pode justificar ainda a redução do passthrough, no caso das exportações totais a partir de 1994.

Além disso, como mostra Schwartz (1999), a média européia desses repasses no ano de 1992 era de 4,5\%, contra uma média brasileira em 1999 de 9,6\%, e contra uma média latino-americana de 25,1\% nos anos 90. Neste último caso, tratava-se de economias altamente indexadas.

Outro aspecto de fundamental importância na explicação do passthrough das variações cambiais para os preços é a questão dos custos industriais, significando que quanto maior o componente de insumos importados, maiores os efeitos compensadores, de forma que os resultados não sejam potencializados nos preços dos bens finais. Britto (2003), a partir de uma análise de insumo produto, mostrou que, no período de 1990 a 1996, além de setores importantes da indústria brasileira - como químicos diversos, farmacêutico, metalúrgico, entre outros - apresentarem alto grau de conteúdo importado em 1990, apenas os setores refino de petróleo e petroquímica e elementos químicos não petroquímicos apresentaram coeficiente de conteúdo importado decrescente, ao longo do período. Os setores veículos, peças e acessórios, beneficiamento de produtos vegetais e fumo, minerais não metálicos, outros metalúrgicos e abate e preparação de carnes, apresentaram coeficiente estável. Todos os demais apresentaram um coeficiente crescente de conteúdo importado. Isso comprometeu os saldos comerciais setoriais e, em muitos casos, tornaram-nos negativos. Além disso - e principalmente no caso das desvalorizações cambiais, se o peso dos insumos importados é relevante, isso contamina os custos dos demais setores industriais internos demandantes de insumos. Obviamente, tal mecanismo dificulta a utilização de ganhos cambiais como mecanismos de conquista de competitividade das exportações.

Tão importante quanto os dois efeitos descritos é o comportamento dos markups em períodos de mudanças cambiais. O movimento esperado ocorre no sentido de que se apenas um percentual - considerado 
baixo, como mostrado acima e também pela literatura - das variações cambiais é repassado para os preços finais, os markups dos exportadores devem crescer. Essa é a conclusão a que chega Ferreira (2000), também compartilhada por Kannebley Jr. (2000). Entretanto, esses autores não levam em consideração os preços dos insumos importados que, quanto mais elevados, tenderão a inibir os efeitos das variações cambiais sobre os preços, de forma que as margens de lucros tenham um comportamento diverso do esperado. Além disso, como a economia brasileira ainda é altamente dependente de insumos importados, as elasticidades-renda das importações tendem a ser maiores que as das exportações. Assim, em período de desvalorizações cambiais, os custos dos importados devem subir significativamente, compensando os efeitos dos ganhos das desvalorizações advindos dos tradeables exportados. Pereira e Carvalho (2000) mostram que, no período de setembro de 1998 a fevereiro e março de 1999, os markups industriais reduziram em média $6 \%$ e, até novembro de 1999 - aproximadamente um ano após a mudança cambial - não tinham recuperado os níveis de fevereiro/março de 1998 - cerca de um ano antes da mudança no regime. Ou seja, os aumentos potenciais das margens de lucro em virtude da desvalorização da taxa de câmbio podem ter sido compensados pelos aumentos de preços dos insumos importados. Daí a redução dos markups nesse período.

Assim, esses baixos coeficientes de pass-through fazem com que as desvalorizações da taxa de câmbio não se traduzam em ganhos significativos de competitividade, uma vez que não reduzem de maneira significativa os preços das exportações em dólares - isso porque o Brasil apresenta pouco controle sobre os preços dos produtos exportados no mercado mundial. Dessa maneira, políticas que visam aumentar as exportações brasileiras via desvalorizações da taxa de câmbio podem não ser o melhor instrumento de fomento às exportações. No entanto, uma desvalorização pode ainda ter impacto sobre o volume das exportações por conta de seu efeito sobre a oferta, uma vez que, com um coeficiente de pass-through relativamente baixo, o preço das exportações em moeda doméstica aumenta, permitindo uma elevação das margens de lucro das empresas exportadoras e possibilitando um incremento da oferta de exportações ${ }^{14}$.

${ }^{14}$ Ver Ferreira (2000, p. 265). 


\section{Conclusões}

O objetivo deste artigo é analisar os determinantes do pass-through das variações da taxa de câmbio para os preços dos principais produtos exportados pelo Brasil. Foram escolhidos para análise os seguintes setores: Peças e outros Veículos; Siderurgia; Extrativa Mineral; Máquinas e Tratores; Veículos Automotores; Óleos Vegetais; Refino de Petróleo, Madeira e Mobiliário; Beneficiamento de Produtos Vegetais; Metalurgia de Não-ferrosos; Celulose Papel e Gráfica; Material Elétrico; Elementos Químicos e Equipamentos Eletrônicos. Esses setores juntos foram responsáveis por aproximadamente $65,86 \%$ das exportações totais brasileiras, no ano 2004. Adicionalmente, para propósitos de comparação, analisaram-se também as Exportações Totais.

Mostrou-se que coeficientes estimados de forma variável no tempo de pass-through da taxa de câmbio para os preços das exportações dos setores analisados, em todos os casos, apresentaram sinal negativo ao longo de todo o período pesquisado - como era esperado teoricamente.

Observou-se também que os coeficientes estimados são relativamente baixos. Em média, para todos os setores, o menor coeficiente médio obtido foi de -0,14 e o máximo foi de -0,34. Esses baixos coeficientes de pass-through fazem com que as desvalorizações da taxa de câmbio não se traduzam em ganhos significativos de competitividade, tendo em vista que não reduzem significativamente os preços das exportações em dólares. Isso, porém, não implica necessariamente aumentos das margens de lucros dos exportadores, já que, se levarmos em consideração os insumos importados, essas margens podem até decrescer.

O estudo pode ser ampliado utilizando dados mais desagregados de setores específicos, a fim de obter estimativas mais precisas do coeficiente de pass-through.

Para concluir, devido à falta de controle sobre o comportamento da taxa de câmbio e os baixos coeficientes estimados de pass-through, existe a necessidade de serem consideradas outras alternativas e políticas para o incremento das exportações do Brasil. 


\section{Referências bibliográficas}

BALDWIN, R. E. Hysteresis in import prices: the beached effect. American Economic Review, v. 78, 1988.

BRITTO, G. Abertura comercial e coeficiente de conteúdo importado na indústria. In: LAPLANE, M. COUTINHO, L. HIRATUKA, C. (Org.) Internacionalização e desenvolvimento da indústria no Brasil. São Paulo: Editora UNESP, 2003.

CAMPA, José; GOLDBERG, Linda. Investment, pass-through, and exchange rates: a cross-country comparison. Mimeografado, 1998.

COUGHLIN, Cletus; POLLARD, Patricia. Exchange rate pass-through in U.S. manufacturing: exchange rate index choice and asymmetry issues. Federal Reserve Bank of St. Louis Working Paper, n. 2000-022A, 2000.

DARVAS, Zsolt. Exchange rate pass-through and the real exchange rate in EU candidate countries. Economic Research Centre of the Deutsche Bank Discussion Paper, n. 10/01, 2001.

DIXIT, Avinash. Hysteresis, import penetration and exchange rate passthrough. Quarterly Journal of Economics, v. 104, 1989.

DORNBUSCH, Rudiger. Exchange rate and prices. American Economic Review, v. 77, n. 1, 1987.

DWYER, Jacqueline; KENT, Christopher; PEASE, Andrew. Exchange rate pass-through: the different responses of importers and exporters. Reserve Bank of Australia Research Discussion Paper, n. 9304, 1993.

FERREIRA, Afonso; SANSO, Andreu. Exchange rate pass-through: the case of brazilian exports of manufactures. In: XII World Congress of International Economics Association, Buenos Aires, 1999.

FERREIRA, Afonso. Pass-through da taxa de câmbio: modelos teóricos e evidências empíricas para as exportações brasileiras de manufaturados. In FONTES, R.; ARBEX, Marcelo (eds.) Economia aberta: ensaios sobre fluxos de capitais, câmbio e exportações. Viçosa: UFV, 2000.

FISCHER, Stanley. A model of exchange rate pass-through. Journal of International Economics, v. 26, 1989. 
GOLDBERG, Pinelopi; KNETTER; Michael. Goods prices and exchange rates: what have we learned? Journal of Economic Literature, n. 5862, 42p., 1997.

GOLDFAJN, Ilan; WERLANG, Sergio. The pass-through from depreciation to inflation: a panel study. Puc-Rio Texto para Discussão, n. 423, p.1-44, 2000.

HARVEY, Andrew. Time series models. Deddington, U.K.: Phillip Alan, 1981.

JUDGE, George; GRIFFITHS, W. E.; CARTER HILL, R.; LUTKEPOHL, Helmut; LEE, Tsoung-Chao. The theory and practice of econometrics. 2 ed. New York: John Wiley and Sons, 1985.

KANNEBLEY JR., Sérgio. Exchange rate pass-through: uma análise setorial para as exportações brasileiras (1984-1997). Economia Aplicada, v. 4, n. 3, 2000.

KIM, Yoonbal. Exchange rates and import prices in the United States: a varying-parameter estimation of exchange-rate pass-through. Journal of Business \& Economic Statistics, v. 8, n. 3, 1990.

KRUGMAN, Paul. Exchange Rate Instability. Cambridge: MIT Press, 1989.

MENON, Jayant. Exchange rate and import prices for a small open economy. Applied Economics, v. 27, 1995.

MENON, Jayant. Exchange rate pass-through. Journal of Economic Surveys, v. 9, n. 2, 1995.

PEREIRA, T.R; CARVALHO, A. Desvalorização cambial e seu impacto sobre os custos e preços industriais no Brasil - uma análise dos efeitos de encadeamento nos setores produtivos. Texto para Discussão, n. 711, IPEA, 2000.

PORTUGAL, Marcelo. Modelos de parâmetros variáveis: uma resenha crítica. Pesquisa e Planejamento Econômico, v. 13, n. 1, 1993.

SCHWARTZ, G. Brazil price developments after the Floating of the Real: the first six months. In: IMF Staff Country Report. FMI, 1999. 
WANG, Kuo-Liang; WU, Chung-Shu. Exchange rate pass-through and industry characteristics: the case of Taiwan`s exports of midstream petrochemical products. NBER Working Paper, n. 5749, p. 1-28, 1996. 


\section{Apêndice}

Tabela A - Resultados das estimações

\begin{tabular}{|c|c|c|c|c|}
\hline \multicolumn{5}{|c|}{ PT-BVEG - Beneficiamento de produtos vegetais } \\
\hline & Coefficient & Std. Error & t-Statistic & Prob. \\
\hline $\mathrm{C}(1)$ & 2,1293 & 0,0503 & 4,2324 & 0,0000 \\
\hline$C(2)$ & 0,8396 & 0,0166 & 5,0597 & 0,0000 \\
\hline ObVar $(1,1)$ & 0,0028 & 0,0770 & 0,0359 & 0,9714 \\
\hline $\operatorname{SSVar}(1,1)$ & 0,0003 & 0,3410 & 0,0008 & 0,9993 \\
\hline Final & $-0,3877$ & 0,0189 & $-20,0502$ & 0,0000 \\
\hline Log Likelihood & & 39,0998 & & \\
\hline $\begin{array}{l}\text { BVEG }=\mathrm{C}(1)+\mathrm{C}(2) \\
\mathrm{PT}=\mathrm{PT}(-1)\end{array}$ & PASA $+\mathrm{PT}^{*}$ & MBIOSA & & \\
\hline R-squared & 0,9466 & \multicolumn{2}{|c|}{ Mean dependent var } & 4,4712 \\
\hline Adjusted R-squared & 0,9461 & \multicolumn{2}{|c|}{ S.D. dependent var } & 0,1456 \\
\hline S.E. of regression & 0,0338 & \multicolumn{2}{|c|}{ Sum squared resid } & 0,1053 \\
\hline Durbin-Watson stat & 1,8865 & & & \\
\hline \multicolumn{5}{|c|}{ PT-PAP - Celulose, papel e gráfica } \\
\hline & Coefficient & Std. Error & t-Statistic & Prob. \\
\hline $\mathrm{C}(1)$ & 2,6140 & 0,0246 & 106,0529 & 0,0000 \\
\hline$C(2)$ & 0,7164 & 0,0077 & 92,9666 & 0,0000 \\
\hline $\operatorname{ObVar}(1,1)$ & 0,0021 & 0,0459 & 0,0458 & 0,9636 \\
\hline $\operatorname{SSVar}(1,1)$ & 0,0001 & 0,7809 & 0,0001 & 0,9999 \\
\hline Final SV1 & $-0,2625$ & 0,0112 & $-23,3799$ & 0,0000 \\
\hline Log Likelihood & & 53,8461 & & \\
\hline \multirow{2}{*}{\multicolumn{5}{|c|}{$\begin{array}{l}\mathrm{PAP}=\mathrm{C}(1)+\mathrm{C}(2) * \text { IPASA }+ \text { PT } * \text { CAMBIOSA } \\
\mathrm{PT}=\mathrm{PT}(-1)\end{array}$}} \\
\hline & & & & \\
\hline R-squared & 0,9808 & \multicolumn{2}{|c|}{ Mean dependent var } & 4,4913 \\
\hline Adjusted R-squared & 0,9806 & \multicolumn{2}{|c|}{ S.D. dependent var } & 0,2155 \\
\hline S.E. of regression & 0,0300 & \multicolumn{2}{|c|}{ Sum squared resid } & 0,0829 \\
\hline Durbin-Watson stat & 1,1526 & & & \\
\hline \multicolumn{5}{|c|}{ PT-QUIM - Elementos químicos } \\
\hline & Coefficient & Std. Error & t-Statistic & Prob. \\
\hline $\mathrm{C}(1)$ & 2,7230 & 0,0174 & 156,5929 & 0,0000 \\
\hline $\mathrm{C}(2)$ & 0,6033 & 0,0058 & 104,8458 & 0,0000 \\
\hline $\operatorname{ObVar}(1,1)$ & 0,0002 & 0,8547 & 0,0003 & 0,9998 \\
\hline $\operatorname{SSVar}(1,1)$ & 0,0000 & 3,7146 & 0,0000 & 1,0000 \\
\hline Final & $-0,2286$ & 0,0064 & $-35,8390$ & 0,0000 \\
\hline Log Likelihood & & 107,2780 & & \\
\hline \multirow{2}{*}{\multicolumn{5}{|c|}{$\begin{array}{l}\text { QUIM }=\mathrm{C}(1)+\mathrm{C}(2) * \text { IPASA }+\mathrm{PT} 1 * \text { CAMBIOSA } \\
\mathrm{PT}=\mathrm{PT}(-1)\end{array}$}} \\
\hline & & & & \\
\hline R-squared & 0,9916 & \multicolumn{2}{|c|}{ Mean dependent var } & 4,5374 \\
\hline Adjusted R-squared & 0,9915 & \multicolumn{2}{|c|}{ S.D. dependent var } & 0,1260 \\
\hline S.E. of regression & 0,0116 & \multicolumn{2}{|c|}{ Sum squared resid } & 0,0124 \\
\hline Durbin-Watson stat & 2,9063 & & & \\
\hline
\end{tabular}




\begin{tabular}{|c|c|c|c|c|}
\hline \multicolumn{5}{|c|}{ PT-EQP - Equipamentos eletrônicos } \\
\hline & Coefficient & Std. Error & t-Statistic & Prob. \\
\hline $\mathrm{C}(1)$ & 2,6093 & 0,0128 & 203,3999 & 0,0000 \\
\hline$C(2)$ & 0,5613 & 0,0040 & 141,9729 & 0,0000 \\
\hline $\operatorname{ObVar}(1,1)$ & 0,0011 & 0,1651 & 0,0066 & 0,9948 \\
\hline $\operatorname{SSVar}(1,1)$ & 0,0000 & $8.033 .656,0000$ & 0,0000 & 1,0000 \\
\hline Final & $-0,1580$ & 0,0054 & $-28,9957$ & 0,0000 \\
\hline Log Likelihood & & 110,0614 & & \\
\hline \multicolumn{5}{|l|}{$\mathrm{EQP}=\mathrm{C}(1)+$} \\
\hline R-squared & 0,9544 & \multicolumn{2}{|c|}{ Mean dependent var } & 4,3655 \\
\hline Adjusted R-squared & 0,9539 & \multicolumn{2}{|c|}{ S.D. dependent var } & 0,1483 \\
\hline S.E. of regression & 0,0319 & \multicolumn{2}{|c|}{ Sum squared resid } & 0,0934 \\
\hline Durbin-Watson stat & 1,6820 & & & \\
\hline \multicolumn{5}{|c|}{ PT-EXT - Extrativa mneral } \\
\hline & Coefficient & Std. Error & t-Statistic & Prob. \\
\hline $\mathrm{C}(1)$ & 2,9196 & 0,0243 & 120,3917 & 0,0000 \\
\hline $\mathrm{C}(2)$ & 0,5504 & 0,0080 & 68,5807 & 0,0000 \\
\hline $\operatorname{ObVar}(1,1)$ & 0,0007 & 0,2636 & 0,0025 & 0,9980 \\
\hline $\operatorname{SSVar}(1,1)$ & 0,0000 & 27,4281 & 0,0000 & 1,0000 \\
\hline Final & $-0,1986$ & 0,0034 & $-58,1337$ & 0,0000 \\
\hline Log Likelihood & & 130,7457 & & \\
\hline \multirow{2}{*}{\multicolumn{5}{|c|}{$\begin{array}{l}\text { PT-EXT }=\mathrm{C}(1)+\mathrm{C}(2) * \text { IPASA }+\mathrm{PT}^{*} \text { CAMBIOSA } \\
\mathrm{PT}=\mathrm{PT}(-1)\end{array}$}} \\
\hline & & & & \\
\hline R-squared & 0,9381 & \multicolumn{2}{|c|}{ Mean dependent var } & 4,5351 \\
\hline Adjusted R-squared & 0,9375 & \multicolumn{2}{|c|}{ S.D. dependent var } & 0,0915 \\
\hline S.E. of regression & 0,0229 & \multicolumn{2}{|c|}{ Sum squared resid } & 0,0482 \\
\hline Durbin-Watson stat & 0,9832 & & & \\
\hline \multicolumn{5}{|c|}{ PT-TOTAL -Exportações totais } \\
\hline & Coefficient & Std. Error & t-Statistic & Prob. \\
\hline $\mathrm{C}(1)$ & 1,1004 & 0,0344 & 32,0278 & 0,0000 \\
\hline$C(2)$ & 0,5173 & 0,0077 & 67,1583 & 0,0000 \\
\hline $\mathrm{C}(3)$ & 0,3842 & 0,0063 & 60,9211 & 0,0000 \\
\hline ObVar $(1,1)$ & 0,0000 & 7,0575 & 0,0000 & 1,0000 \\
\hline $\operatorname{SSVar}(1,1)$ & 0,0000 & 12,3628 & 0,0000 & 1,0000 \\
\hline Final & $-0,1714$ & 0,0046 & $-37,1250$ & 0,0000 \\
\hline Log Likelihood & & 153,8246 & & \\
\hline \multicolumn{5}{|c|}{$\begin{array}{l}\text { TOTAL }=\mathrm{C}(1)+\mathrm{C}(2) * \text { IPASA }+\mathrm{C}(3) * \text { PEXMUSA }+ \text { PT } * \text { CAMBIOSA } \\
\text { PT }=\text { PT }(-1)\end{array}$} \\
\hline R-squared & 0,9959 & \multicolumn{2}{|c|}{ Mean dependent var } & 4,4625 \\
\hline Adjusted R-squared & 0,9958 & \multicolumn{2}{|c|}{ S.D. dependent var } & 0,0804 \\
\hline S.E. of regression & 0,0052 & \multirow{2}{*}{\multicolumn{2}{|c|}{ Sum squared resid }} & 0,0024 \\
\hline Durbin-Watson stat & 2,6573 & & & \\
\hline
\end{tabular}




\begin{tabular}{|c|c|c|c|c|}
\hline \multicolumn{5}{|c|}{ PT-MAD - Madeira e mobiliário } \\
\hline & Coefficient & Std. Error & t-Statistic & Prob. \\
\hline $\mathrm{C}(1)$ & 2,3771 & 0,0148 & 160,3142 & 0,0000 \\
\hline$C(2)$ & 0,6359 & 0,0052 & 121,5262 & 0,0000 \\
\hline $\operatorname{ObVar}(1,1)$ & 0,0003 & 0,8166 & 0,0004 & 0,9997 \\
\hline $\operatorname{SSVar}(1,1)$ & 0,0000 & 7,8237 & 0,0000 & 1,0000 \\
\hline Final & $-0,1986$ & 0,0056 & $-35,1558$ & 0,0000 \\
\hline Log Likelihood & \multicolumn{4}{|c|}{117,3786} \\
\hline \multicolumn{5}{|c|}{$\begin{array}{l}\mathrm{MAD}=\mathrm{C}(1)+\mathrm{C}(2) * \text { IPASA }+\mathrm{PT}^{*} \text { CAMBIOSA } \\
\mathrm{PT}=\mathrm{PT}(-1)\end{array}$} \\
\hline R-squared & 0,9952 & \multicolumn{2}{|c|}{ Mean dependent var } & 4,3193 \\
\hline Adjusted R-squared & 0,9951 & \multicolumn{2}{|c|}{ S.D. dependent var } & 0,2083 \\
\hline S.E. of regression & 0,0145 & \multicolumn{2}{|c|}{ Sum squared resid } & 0,0194 \\
\hline Durbin-Watson stat & 1,6908 & & & \\
\hline \multicolumn{5}{|c|}{ PT-MNF - Metalurgia não ferrosos } \\
\hline & Coefficient & Std. Error & t-Statistic & Prob. \\
\hline $\mathrm{C}(1)$ & 2,9776 & 0,0445 & 66,9102 & 0,0000 \\
\hline $\mathrm{C}(2)$ & 0,5602 & 0,0144 & 39,0213 & 0,0000 \\
\hline $\operatorname{ObVar}(1,1)$ & 0,0102 & 0,0112 & 0,9061 & 0,3673 \\
\hline $\operatorname{SSVar}(1,1)$ & 0,0000 & 5,2083 & 0,0000 & 1,0000 \\
\hline Final & $-0,2171$ & 0,0077 & $-28,3322$ & 0,0000 \\
\hline Log Likelihood & \multicolumn{3}{|c|}{53,7795} & \\
\hline \multicolumn{5}{|c|}{$\mathrm{MNF}=\mathrm{C}(1)+\mathrm{C}(2) *$ IPASA + PT $*$ CAMBIOSA } \\
\hline R-squared & 0,5601 & \multicolumn{2}{|c|}{ Mean dependent var } & 4,5713 \\
\hline Adjusted R-squared & 0,5554 & \multicolumn{2}{|c|}{ S.D. dependent var } & 0,1472 \\
\hline S.E. of regression & 0,0981 & \multicolumn{2}{|c|}{ Sum squared resid } & 0,8860 \\
\hline Durbin-Watson stat & 0,3306 & & & \\
\hline \multicolumn{5}{|c|}{ PT-ELET - Material elétrico } \\
\hline & Coefficient & Std. Error & t-Statistic & Prob. \\
\hline $\mathrm{C}(1)$ & 2,8432 & 0,0334 & 85,1722 & 0,0000 \\
\hline $\mathrm{C}(2)$ & 0,5204 & 0,0111 & 46,8712 & 0,0000 \\
\hline $\operatorname{ObVar}(1,1)$ & 0,0006 & 0,3571 & 0,0015 & 0,9988 \\
\hline $\operatorname{SSVar}(1,1)$ & 0,0000 & 20,9199 & 0,0000 & 1,0000 \\
\hline Final & $-0,1762$ & 0,0038 & $-46,9228$ & 0,0000 \\
\hline Log Likelihood & & 131,3006 & & \\
\hline \multicolumn{5}{|c|}{$\begin{array}{l}\mathrm{ELET}=\mathrm{C}(1)+\mathrm{C}(2) * \text { IPASA }+ \text { PT*CAMBIOSA } \\
\mathrm{PT}=\mathrm{PT}(-1)\end{array}$} \\
\hline R-squared & 0,9855 & \multicolumn{2}{|c|}{ Mean dependent var } & 4,3504 \\
\hline Adjusted R-squared & 0,9853 & \multicolumn{2}{|c|}{ S.D. dependent var } & 0,1660 \\
\hline S.E. of regression & 0,0201 & \multicolumn{2}{|c|}{ Sum squared resid } & 0,0373 \\
\hline Durbin-Watson stat & 1,5140 & & & \\
\hline
\end{tabular}




\begin{tabular}{|c|c|c|c|c|}
\hline \multicolumn{5}{|c|}{ PT-MAQ - Máquinas e tratores } \\
\hline & Coefficient & Std. Error & t-Statistic & Prob. \\
\hline $\mathrm{C}(1)$ & 2,8494 & 0,0127 & 223,8173 & 0,0000 \\
\hline $\mathrm{C}(2)$ & 0,5229 & 0,0041 & 127,6177 & 0,0000 \\
\hline $\operatorname{ObVar}(1,1)$ & 0,0010 & 0,1366 & 0,0073 & 0,9942 \\
\hline $\operatorname{SSVar}(1,1)$ & 0,0000 & 18,4109 & 0,0000 & 1,0000 \\
\hline Final & $-0,1631$ & 0,0039 & $-42,1322$ & 0,0000 \\
\hline Log Likelihood & & 110,6206 & & \\
\hline $\begin{array}{l}\mathrm{MAQ}=\mathrm{C}(1)+\mathrm{C}(2) \\
\mathrm{PT}=\mathrm{PT}(-1)\end{array}$ & $\mathrm{PASA}+\mathrm{PT}^{*} \mathrm{C}$ & MBIOSA & & \\
\hline R-squared & 0,9662 & \multicolumn{2}{|c|}{ Mean dependent var } & 4,3807 \\
\hline Adjusted R-squared & 0,9658 & \multicolumn{2}{|c|}{ S.D. dependent var } & 0,1815 \\
\hline S.E. of regression & 0,0336 & \multicolumn{2}{|c|}{ Sum squared resid } & 0,1036 \\
\hline Durbin-Watson stat & 1,1559 & & & \\
\hline \multicolumn{5}{|c|}{ PT-OVEG - Óleos vegetais } \\
\hline & Coefficient & Std. Error & t-Statistic & Prob. \\
\hline $\mathrm{C}(1)$ & 2,6369 & 0,0309 & 85,2193 & 0,0000 \\
\hline $\mathrm{C}(2)$ & 0,5865 & 0,0099 & 59,1414 & 0,0000 \\
\hline ObVar $(1,1)$ & 0,0017 & 0,0779 & 0,0216 & 0,9828 \\
\hline $\operatorname{SSVar}(1,1)$ & 0,0000 & 1,9021 & 0,0000 & 1,0000 \\
\hline Final & $-0,2242$ & 0,0085 & $-26,3456$ & 0,0000 \\
\hline Log Likelihood & & 81,0528 & & \\
\hline \multicolumn{5}{|c|}{$\begin{array}{l}\text { OVEG }=\mathrm{C}(1)+\mathrm{C}(2) * \text { IPASA }+\mathrm{PT}^{*} \text { CAMBIOSA } \\
\mathrm{PT}=\mathrm{PT}(-1)\end{array}$} \\
\hline R-squared & 0,9505 & \multicolumn{2}{|c|}{ Mean dependent var } & 4,3995 \\
\hline Adjusted R-squared & 0,9500 & \multicolumn{2}{|c|}{ S.D. dependent var } & 0,1390 \\
\hline S.E. of regression & 0,0311 & \multicolumn{2}{|c|}{ Sum squared resid } & 0,0890 \\
\hline Durbin-Watson stat & 0,9958 & & & \\
\hline \multicolumn{5}{|c|}{ PT-POV - Peças e outros veículos } \\
\hline & Coefficient & Std. Error & t-Statistic & Prob. \\
\hline$C(1)$ & 2,9426 & 0,0629 & 46,8021 & 0,0000 \\
\hline $\mathrm{C}(2)$ & 0,5090 & 0,0212 & 24,0085 & 0,0000 \\
\hline $\operatorname{ObVar}(1,1)$ & 0,0005 & 0,3122 & 0,0017 & 0,9986 \\
\hline $\operatorname{SSVar}(1,1)$ & 0,0001 & 1,6239 & 0,0000 & 1,0000 \\
\hline Final & $-0,1150$ & 0,0090 & $-12,7554$ & 0,0000 \\
\hline Log Likelihood & & 99,4140 & & \\
\hline \multicolumn{5}{|c|}{$\begin{array}{l}\mathrm{POV}=\mathrm{C}(1)+\mathrm{C}(2) * \text { IPASA }+\mathrm{PT}^{*} \text { CAMBIOSA } \\
\mathrm{PT}=\mathrm{PT}(-1)\end{array}$} \\
\hline R-squared & 0,9950 & \multicolumn{2}{|c|}{ Mean dependent var } & 4,3539 \\
\hline Adjusted R-squared & 0,9950 & \multicolumn{2}{|c|}{ S.D. dependent var } & 0,2312 \\
\hline S.E. of regression & 0,0164 & \multicolumn{2}{|c|}{ Sum squared resid } & 0,0247 \\
\hline Durbin-Watson stat & 2,4103 & & & \\
\hline
\end{tabular}




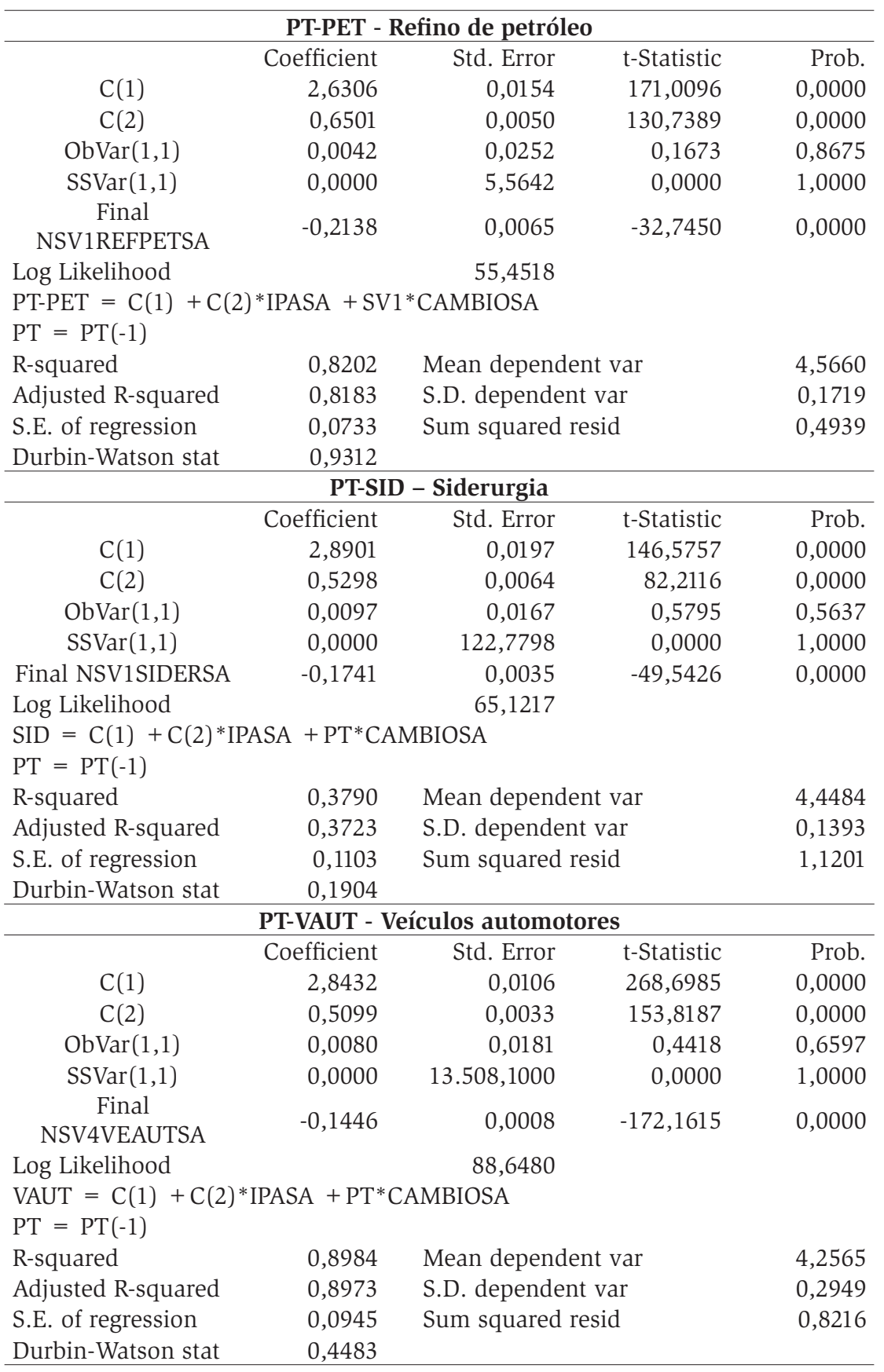


Tabela B. Coeficiente de pass-through médio por setores

\begin{tabular}{lrrrr} 
& \multicolumn{4}{c}{ Períodos } \\
\cline { 2 - 5 } \multicolumn{1}{c}{ Setores } & $\mathbf{1 9 8 1 . 1 / 1 9 9 4 . 2}$ & $\mathbf{1 9 9 4 . 3 / 2 0 0 4 . 1}$ & $\mathbf{1 9 9 4 . 3 / 1 9 9 8 . 4}$ & $\mathbf{1 9 9 1 . 1 / 2 0 0 4 . 1}$ \\
\hline PT-EXPOR_SM & $-0,1854$ & $-0,1549$ & $-0,1433$ & $-0,1648$ \\
PT-BVEG_SM & $-0,2741$ & $-0,3318$ & $-0,3443$ & $-0,3210$ \\
PT-ELET_SM & $-0,1564$ & $-0,1598$ & $-0,1713$ & $-0,1499$ \\
PT-EQP_SM & $-0,1876$ & $-0,1512$ & $-0,1558$ & $-0,1473$ \\
PT-EXT_SM & $-0,1730$ & $-0,1874$ & $-0,1908$ & $-0,1845$ \\
PT-MAD_SM & $-0,2038$ & $-0,1763$ & $-0,1865$ & $-0,1676$ \\
PT-MAQ_SM & $-0,1604$ & $-0,1553$ & $-0,1661$ & $-0,1459$ \\
PT-MNF_SM & $-0,1913$ & $-0,2208$ & $-0,2269$ & $-0,2156$ \\
PT-OVEG_SM & $-0,2042$ & $-0,2019$ & $-0,2096$ & $-0,1952$ \\
PT-PET_SM & $-0,2172$ & $-0,2282$ & $-0,2328$ & $-0,2242$ \\
PT-POV_SM & $-0,1445$ & $-0,1597$ & $-0,1767$ & $-0,1452$ \\
PT-QUIM_SM & $-0,2076$ & $-0,2150$ & $-0,2253$ & $-0,2061$ \\
PT-SID_SM & $-0,1707$ & $-0,1716$ & $-0,1707$ & $-0,1724$ \\
PT-VAUT_SM & $-0,1447$ & $-0,1446$ & $-0,1446$ & $-0,1446$ \\
PT-PAP_SM & $-0,2232$ & $-0,2864$ & $-0,2981$ & $-0,2764$ \\
\hline
\end{tabular}

